\title{
Correlates of Health Locus of Control among Patients Diagnosed with Type-II Diabetes Mellitus
}

\author{
Dina N. Al Nawafa'h', Ayman M. Hamdan-Mansour ${ }^{2 *}$ \\ ${ }^{1}$ Diabetic Nurse, Royal Medical Services, Amman, Jordan \\ ${ }^{2}$ Department of Community Health Nursing, Faculty of Nursing, The University of Jordan, Amman, Jordan \\ Email: d.nasri@yahoo.com, ${ }^{*}$ a.mansour@ju.edu.jo, ${ }^{*}$ aymanjabay@gmail.com
}

Received 7 August 2015; accepted 18 August 2015; published 21 August 2015

Copyright (C) 2015 by authors and Scientific Research Publishing Inc.

This work is licensed under the Creative Commons Attribution International License (CC BY).

http://creativecommons.org/licenses/by/4.0/

(c) (i) Open Access

\section{Abstract}

Background: The comorbidity between chronic physical conditions and psychosocial health became common interest for health professional and researchers. The purpose of this study was to investigate the relationship among health locus of control, self efficacy, and demographic factors in patients with type-II diabetes mellitus. Method: Data were collected using cross-sectional, correaltional design from 793 patients with type-II diabetes in regards to health locus of control (HLOC) self-efficacy, and biomarkers. Results: The mean score for the internal subscale of HLOC was 27.2 ( $S D=6.32$ ), for the powerful others subscale of HLOC it was 30.9 (SD = 5.7), and for chance subscale of HLOC it was $18.6(\mathrm{SD}=6.8)$. The mean total score of locus of control scale was 76.8 (SD = 13.1) ranging from 19 to 132 . The mean score of HbA1C was 7.5 (SD = 2.6). Patients had moderate to high perception of powerful other health locus of control, and self efficacy. Results also showed that locus of control had positive and significant correlation with self efficacy $(r=$ $0.18, p>0.01)$ and negative relationship with $\mathrm{HbA1C}(r=-0.11, p>0.01)$. On the other hand, age has no significant correlation with health locus of control. Conclusion: Health care professionals need to enhance patient's self-efficacy and internal power of their patients for better health outcomes. Nurses and other health professionals need to emphasize the psychosocial health aspects of patients with chronic illnesses, and in particular, those diagnosed with type-II diabetes mellitus.

\section{Keywords}

Health Locus of Control, Internality, Externality, DM

\footnotetext{
${ }^{*}$ Corresponding author.
}

How to cite this paper: Al Nawafa'h, D.N. and Hamdan-Mansour, A.M. (2015) Correlates of Health Locus of Control among Patients Diagnosed with Type-II Diabetes Mellitus. Journal of Diabetes Mellitus, 5, 190-197. 


\section{Introduction}

Health locus of control has a significant role in role in adaptation to chronic illness and successful health care plans [1]. Health locus control (HLC) refers to a person's beliefs about control over his or her health and the extent of an individual's perceived control over health outcomes [2]. Therefore, such a belief determines how much effort the patient is contributing to his care plan and regimen. HLC could be internal, external powerful others, or external chance [2]. In the internal domain individuals assume responsibility for their conducts and health outcomes. In the external powerful others, the individual believes that others, such as health professionals, are responsible for one's health, while individuals in the external chance believe that their health is controlled by chances and luck [2]. Studies proved that HLOC moderated health behaviors and adherence to health treatment plans [3]. Those with high internality had more positive outcomes on their health conditions, while those with low internality and high externality had poor health outcomes and felt less able to control their health and complications of their illnesses [4]-[7]. Others found that patients with high level of internal locus of control had developed effective strategies to control their pain [7]. Moreover, previous studies reported positive association among health internal locus of control (HLOC) beliefs, psychological factors and biological measures of physical health and survival [8].

Patients' psychosocial status interferes with their ability to manage their needs independently that may exacerbate their health condition. For example, self efficacy has a direct impact on individuals' health outcomes [9] [10]. The impact of chronic illnesses such as diabetes mellitus on the bio-psycho-social aspects of individual's health and wellbeing is associated with difficulties of individuals' adjustment to their illnesses and the evolved changes of their lifestyle [11] [12]. Factors such as health locus of control and self-efficacy are considered significant ones for health care professionals, in particular with the nature of treatment plans for patients with diabetes mellitus type-II and the high level of nonadherence [13]. In general, patients in different health care settings want to assume more control and involvement in decision-making [14]. The holistic management of diabetes requires adequate attention focusing not only on the prevalence of psychosocial health problems but also on the subclinical indicators of distress such as patients' locus of control and self efficacy.

The link between health locus of control and health outcomes has been established in the research [1]. However, factors that enhance or moderate locus of control have not been investigated adequately. For example, education level has been found to influence patient orientation and belief of locus of control [15]. However, using paternal model of care has negatively associated with internal health locus of control among hospitalized patients [15].

In general, the literature shows positive impacts of high levels of HLOC on patient's health outcomes. However, the available information related to the relationship between patients' demographic and personal characteristics and their HLOC had little attention in the literature. The literature provided evidence on the general description of patients' locus of control [7] and focused also on the differences in a specific issue of health care treatment plan [8]. In Jordan most of the studies were focused mainly on assessing the psychological status of patients with chronic illnesses including diabetes [16]-[20]. However, locus of control has been ignored. This study came to address the demographic characteristics of patients and its relationship to patients' health locus of control. The study will add to our understanding for the personal and psychological factors of patients diagnosed with DM that may influence their involvement in health care plans. The study will also enable health professional to use available information about the patient to enhance partnership in health care services. Thus, the purpose of this study was to examine the sociodemographic and psychological correlates of health locus of control among patients diagnosed with diabetes mellitus type-II at the Jordanian general health care settings.

The specific aims are:

1) To identify health locus of control among patients diagnosed with diabetes mellitus type-II at the Jordanian general health care settings;

2) To examine the relationship among self efficacy, health locus of control and demographic and personal characteristics of patients diagnosed with diabetes mellitus type-II at the Jordanian general health care settings.

\section{Methods}

Design: This is a quantitative study using cross-sectional correlational design to collect data in regards to health locus of control and self-efficacy from patients diagnosed with type-II diabetes mellitus. Data were collected using structured interview format from Jordanians patients diagnosed with diabetes type-II attended the 
National Center for Diabetes, Endocrinology and Genetics in Amman, Jordan.

Sample and Sampling: A convenience sample of 791 patients diagnosed with type-II diabetes mellitus represented the sample of this study. Inclusion criteria were: 1) at aged of 18 years or older with type-II diabetes mellitus, and 2) able to read and write Arabic. Exclusion criteria included: 1) no history of diagnosed mental or cognitive disorders that may interfere with their ability to answer the survey questions.

Setting: Patients were recruited from the National Center for Diabetes, Endocrinology and Genetics (NCDEG). The NCDEG center was established in Amman in 1998 as one of the centers attached to the Higher Council for Science and Technology. The center is considered to be the only specialized national center for diabetes, endocrinology and genetics in Jordan, and targeted by Jordanians and neighboring countries.

Data Collection: Prior data collection, ethical approval was obtained from NCDEG. A package of three selfreport questionnaires and an author-developed demographic survey were used in this study. The package had a cover letter that includes information about the purpose of the study, its significance, what is expected from them, and contact information of the principal investigator for any further information and for answering the questions related to the study only. Patients had the chance to have all their questions answered.

\section{Instruments}

The data collected using an Arabic version of self-reporting questionnaires. The Instruments were:

1) Health Locus of Control was measured using the Multidimensional Health Locus of Control Scale (MHLC Form C) [21]. Athe Arabic CVersion of this cale was used [1]. The scale is formed of three main subscales; internal subscale, chance, and powerful others. Each subscale contained six items with Likert responses, ranging from 1 (strongly disagree) to 6 (strongly agree) with a possible subscale score range of 6 - 36. Higher scores reflected stronger beliefs. The subscales were reportedly internally consistent with Cronbach's $\alpha$ ranging from 0.67 (external) to 0.77 (internal) [21]. The scale showed good reliability with Cronbach's $\alpha$ ranging from .72 (external subscale) to 0.64 (internal subscale). In this study, Cronbach's $\alpha$ was good ranging from 0.79 (external subscale) to 0.73 (chance) [1].

2) Self-Efficacy was measured using the Self-Efficacy for Diabetes scale [22]. SED is an eight-items scale used to measure patients feeling of confidence in manage their illness. Patients are asked to rate their response on a visual analogue scale ranging from 1 (not at all confident) to 10 (totally confident). Higher score on the scale indicates higher self-efficacy and lower score indicate low self-efficacy. The scale has good internal consistency with Chronbach's alpha of 0.76. In this study, Chronbach's alpha of 0.81 [22].

Potential Covariates: Gender, age, marital status, type of DM, duration of DM, smoking status, education level and work status and biomarkers such as HbAlc.

\section{Results}

\subsection{Descriptive Characteristics}

A total of 860 patients approached and 793 of them completed and returned the questionnaire forming $92.2 \%$ response rate. The analysis showed that age of the patients ranged from 19 to 85 years with mean age of 54.8 years $(\mathrm{SD}=11.5)$. There were $359(45.3 \%)$ male patients and $434(54.7 \%)$ female patients. About $82.0 \%(\mathrm{n}=$ 650) $82.0 \%$ were married; $5.5 \%(\mathrm{n}=44)$ were single; $11 \%(\mathrm{n}=88)$ were widowed; and $1.4 \%(\mathrm{n}=11)$ were divorced. Among the patients, $35.9 \%(\mathrm{n}=285)$ reported that they are not working, while $22.8 \%(\mathrm{n}=238)$ were working full time; $5.5 \%(n=44)$ were working part time; and $28.7 \%(n=228)$ were retired. Regarding the type of treatment that the patient receive, the majority of them $(59.5 \%, \mathrm{n}=472)$ reported that they were receiving oral medication, while $23.7 \%(\mathrm{n}=188)$ reported that they receive oral medication and insulin and $14.1 \% \mathrm{~b}(\mathrm{n}=$ 112) received only insulin therapy. Also, the analysis showed that $52 \%(\mathrm{n}=412)$ of the patients reported controlled HbAlc; $14.2 \%(n=113)$ fairly controlled and 33.8\% $(n=268)$ poor glycemic control (Table 1$)$.

\subsection{Health Locus of Control}

In regards to patients' health locus of control the analysis (see Table 2) showed that the mean score for the internal subscale was $27.2(\mathrm{SD}=6.0)$, for the powerful others subscale was $30.8(\mathrm{SD}=5.2)$, and for chance subscale was 18.6 $(\mathrm{SD}=6.6)$. The mean total score of locus of control scale was $76.6(\mathrm{SD}=12.7)$ ranging from 19 
Table 1. Demographic characteristic of the sample $(n=793)$.

\begin{tabular}{|c|c|c|c|c|c|c|c|c|}
\hline \multicolumn{2}{|c|}{ Variable } & $\mathrm{n}$ & $\%$ & $\mathrm{M}$ & $\mathrm{SD}$ & $\mathrm{P}_{50}$ & Min & Max \\
\hline \multicolumn{2}{|c|}{ Age } & -- & -- & 54.8 & 11.5 & 55 & 19 & 85 \\
\hline \multirow{2}{*}{ Gender } & Male & 359 & 45.3 & \multirow{2}{*}{--} & \multirow{2}{*}{--} & \multirow{2}{*}{--} & \multirow{2}{*}{--} & \multirow{2}{*}{--} \\
\hline & Female & 434 & 54.7 & & & & & \\
\hline \multirow{4}{*}{ Marital status } & Single & 44 & 5.5 & \multirow{4}{*}{--} & \multirow{4}{*}{--} & \multirow{4}{*}{-- } & \multirow{4}{*}{-- } & \multirow{4}{*}{--} \\
\hline & Married & 650 & 82 & & & & & \\
\hline & Divorced & 11 & 1.4 & & & & & \\
\hline & Widow & 88 & 11 & & & & & \\
\hline \multirow{4}{*}{$\begin{array}{l}\text { Level of } \\
\text { education }\end{array}$} & $>$ High school & 194 & 24.5 & \multirow{5}{*}{--} & \multirow{5}{*}{--} & \multirow{5}{*}{--} & \multirow{5}{*}{--} & \multirow{5}{*}{--} \\
\hline & High school & 165 & 20.9 & & & & & \\
\hline & Diploma & 153 & 19.3 & & & & & \\
\hline & Baccalaureate & 213 & 26.9 & & & & & \\
\hline \multirow{6}{*}{ Working status } & Graduate & 67 & 8.5 & & & & & \\
\hline & Not working & 285 & 35.9 & \multirow{5}{*}{--} & \multirow{5}{*}{--} & \multirow{5}{*}{--} & \multirow{4}{*}{--} & \multirow{4}{*}{--} \\
\hline & Full time job & 236 & 22.8 & & & & & \\
\hline & Part-time job & 44 & 5.5 & & & & & \\
\hline & Retired & 228 & 28.7 & & & & & \\
\hline & Diet & 20 & 2.5 & & & & & \\
\hline \multirow{4}{*}{$\begin{array}{l}\text { Type of } \\
\text { treatment }\end{array}$} & Oral medication & 472 & 59.5 & \multirow{3}{*}{--} & & & & \\
\hline & Insulin & 112 & 14.1 & & -- & -- & -- & -- \\
\hline & $\begin{array}{l}\text { Oral medication } \\
\quad \& \text { insulin }\end{array}$ & 188 & 23.7 & & & & & \\
\hline & None & 373 & 47 & & & & & \\
\hline & Hypertension & 264 & 33.3 & & & & & \\
\hline Diabetic & Retinopathy & 39 & 4.9 & & & & & \\
\hline complications & Nephropathy & 2 & 0.3 & & & & & \\
\hline & Amputation & 5 & 0.6 & & & & & \\
\hline & Others & 109 & 13.7 & & & & & \\
\hline & Smoker & 124 & 15.6 & & & & & \\
\hline Smoking status & Ex-smoker & 80 & 10.1 & -- & -- & -- & -- & -- \\
\hline & Non-smoker & 589 & 74.3 & & & & & \\
\hline $\begin{array}{r}\text { Duration of d } \\
\text { diabetes }\end{array}$ & $\begin{array}{l}\text { liagnosis with } \\
\text { mellitus }\end{array}$ & -- & -- & 85.7 & 82.1 & 60 & 2 & 420 \\
\hline $\mathrm{HbA}$ & $\mathrm{A} 1 \mathrm{C}$ & -- & -- & 7.5 & 2.6 & 7 & 1 & 68 \\
\hline Duration of ins & sulin treatment & -- & -- & 16.5 & 38.1 & 0 & 0 & 360 \\
\hline
\end{tabular}

Patients' HLOC.

to 132 . The results indicate that patients believed that their health outcomes were dependent on powerful others more than themselves or due to chance. The lowest mean score among the subscales was the chance subscale inferring that patients believe that chance has a minimal role in determining their health outcomes. However, patients believed that others such as health professionals, family members and friends have more control on their health outcome than they do themselves. The item analysis has also validated that patients perceived that po- 
Table 2. Descriptive analysis of health locus of control and self-efficacy $(n=793)$.

\begin{tabular}{cccccccc}
\hline Variable & $\mathrm{M}$ & $\mathrm{SD}$ & $\mathrm{P}_{25}$ & $\mathrm{P}_{50}$ & $\mathrm{P}_{75}$ & Min & Max \\
\hline Self-efficacy & 52.4 & 15.5 & 41 & 54 & 64 & 8 & 80 \\
Locus of control & & & & & & & \\
Internality & 27.2 & 6 & 24 & 28 & 32 & 6 & 36 \\
Chance & 18.6 & 6.6 & 14 & 18 & 23 & 6 & 36 \\
Powerful other & 30.8 & 5.2 & 29 & 32 & 35 & 6 & 37 \\
Total scale & 76.6 & 12.7 & 69 & 78 & 85 & 19 & 108 \\
\hline
\end{tabular}

werful others have the greater influence on their health outcomes.

The analysis showed that the items that have the higher mean scores were of the powerful subscale and those were item 5 "Whenever my condition worsens, I should consult a medically trained professional" $(\mathrm{M}=5.5, \mathrm{SD}$ $=1.2)$ and item 3 "If I see my doctor regularly, I am less likely to have problems with my condition" $(\mathrm{M}=5.4$, $\mathrm{SD}=1.2)$. On the other hand, the lowest mean scores have been observed among the chance subscale and those were item 11 "Whatever improvement occurs with my condition is largely a matter of good fortune" $(\mathrm{M}=2.3$, $\mathrm{SD}=1.7)$ and item 9 "Luck plays a big part in determining how my condition improves" $(\mathrm{M}=2.4, \mathrm{SD}=2.3)$.

\subsection{Patients' Self-Efficacy}

Regarding patients' perception of self efficacy, the analysis showed that patients had moderate level of perception of efficacy that they are able to manage their health need related to their illness. The analysis (see Table 2) showed that the mean score was $52.4(\mathrm{SD}=15.5)$ with scores ranging from 8 to 80 . About $50 \%$ of the patients had a score between 41 and 64 and also $50 \%$ of them had a score of 54 or above.

The highest mean score observed in the item "How confident do you feel that you can judge when the changes in your illness mean you should visit the doctor?" $(\mathrm{M}=8.2, \mathrm{SD}=2.5)$, and the lowest was of the item "How confident do you feel that you can exercise 15 to 30 minutes, 4 to 5 times a week?" $(M=5.2, S D=3.4)$.

\subsection{Interrelationship between the Variables of the Study}

In regards to the relationship between self efficacy and health locus of control, and demographic variables, the analysis (see Table 3 ) using correlation matrix showed that health locus of control has positive and significant correlation with self efficacy $(\mathrm{r}=0.18, \mathrm{p}<0.01)$ and negative relationship with $\mathrm{HbA1C}(\mathrm{r}=-0.11, \mathrm{p}<0.01)$. On the other hand, age has no significant correlation with health locus of control.

\subsection{Difference in Health Locus of Control and Self Efficacy, Related to Demographic Variables}

In regards to differences in health locus of control related to demographic variables, the analysis using t-test (see Table 4) showed that there was a significant difference in health locus of control in regards to level of education $\left(\mathrm{F}_{6,792}=2.3, \mathrm{p}=0.04\right)$. Using post hoc comparison (Tukey HSD), the analysis showed that the difference was between those who have high school and those with bachelor degree.

The analysis also showed that there was a significant difference in health locus of control in regards type of complications $\left(\mathrm{F}_{5,792}=4.7, \mathrm{p}<0.001\right)$. Using post hoc comparison (Tukey HSD), the analysis showed that the difference was between those who have no complications and those who have nephropathy and had amputation. Also the difference was between those who have nephropathy and those who have hypertension and retinopathy. The analysis also showed that there was a significant differences in self efficacy in relation to working status $\left(\mathrm{F}_{4,792}=4.2, \mathrm{p}=0.002\right)$. Using post hoc comparison (Tukey HSD), the analysis showed that the difference was between those who are not working and those who are retired. Moreover, the analysis showed that

\section{Discussion}

HLOC beliefs influence patients' health behaviors and illustrate how dependent the patients are on themselves, 
Table 3. Correlation between health locus of control, self efficacy, and demographic variables.

\begin{tabular}{|c|c|c|c|c|c|c|c|c|}
\hline Variables & $\begin{array}{c}\text { Self } \\
\text { efficacy }\end{array}$ & HLOC-total & Internality & Chance & $\begin{array}{c}\text { Powerful } \\
\text { others }\end{array}$ & Age & $\begin{array}{c}\text { Duration of } \\
\text { insulin therapy }\end{array}$ & $\mathrm{HbA1C}$ \\
\hline \multicolumn{9}{|l|}{ Self efficacy } \\
\hline HLOC-total & $0.18^{* *}$ & 0. & & & & & & \\
\hline Internality & $0.16^{* *}$ & $0.76^{* *}$ & 0. & & & & & \\
\hline chance & 00.05 & $0.65^{* *}$ & $0.14^{* *}$ & 0. & & & & \\
\hline Powerful others & $0.19^{* *}$ & $0.74^{* *}$ & $0.52^{* *}$ & $0.15^{* *}$ & 0. & & & \\
\hline Age & 00.01 & 00.06 & -00.01 & $0.08^{*}$ & 00.05 & & & \\
\hline $\begin{array}{l}\text { Duration of } \\
\text { insulin therapy }\end{array}$ & -00.03 & 00.01 & 00.02 & 00.01 & -00.02 & $0.08^{*}$ & & \\
\hline $\mathrm{HbA1C}$ & $-0.11^{* *}$ & -00.02 & -00.02 & 00.04 & -00.05 & 00.03 & $0.28^{* *}$ & . \\
\hline
\end{tabular}

${ }^{* *}$ Correlation is significant at the 0.01 level (2-tailed); ${ }^{*}$ Correlation is significant at the 0.05 level (2-tailed).

Table 4. Difference in self efficacy, health locus of control related to demographic variables $(n=793)$.

\begin{tabular}{cccc}
\hline & \multicolumn{2}{c}{ Test statistics } & \\
\hline Variable & $\mathrm{F}$ & $\mathrm{p}$-value & Group difference \\
\hline Locus of control X level of education & 2.3 & $>0.04$ & High school X bachelor degree \\
X type of complication & 4.7 & $>0.001$ & Nephropathy X amputation. nephropathy X hypertension \\
& & & Nephropathy X retinopathy \\
Self efficacy X working status & 4.2 & 0.002 & Not working X retired \\
\hline
\end{tabular}

their health professionals, or on chance in managing their health. Equally, nurses' perception of patients' health locus of control have implications for whether nurses encourage patients to play an active role in managing their health or having their patients depends on them or on chance. Therefore, partnership requires that both patients and nurses have an agreement on the how health care plan should be achieved. High agreement will reflect the efforts made by nurses and patients to enhance partnership in health care plan and management.

The Findings showed that patients reported that their health outcomes mainly influenced by the powerful others rather than themselves or by chances. Also the study found that patients had moderate level of perception of self-efficacy. The findings in this study agree with previous ones who found that patients diagnosed with chronic illnesses believed that their health is more influenced by health professionals and friends and family members rather than themselves or chance [1] [23]. One explanation is that long experience of illness may influenced patients' perception of their HLOC that may contribute to higher level of perception of external HLOC than other forms [24]. However, patients' perception of high external HLOC was associated with patients' adherence to treatment plans than those with internal HLOC [25]. Regarding patients perceptions of self-efficacy, the present findings showed that patients had moderate level of perception of self-efficacy that corresponds with previous international studies that found moderate to high level of self efficacy among patients diagnosed with DM-II [26]-[28]. The moderate and high level of self efficacy, according to literature; have been associated with positive outcome of quality of life and social support among people with type-II diabetes.

This study is first to address this issue among patients with diabetes mellitus, however; in comparison with other studies targeting patients with chronic illness the results agree to those reports. One limitation for this study is that data collected from patients referred to the NCDEG, while multisite convenience sample may produce alternative reports.

\section{Conclusion}

This study has showed that patients with type-II diabetes mellitus in Jordan have moderate to high levels of po- 
werful others - health locus of control, and self efficacy. Also the study found that there was a positive association between locus of control and self efficacy. It is recommended that health care professionals should enhance patient's self-efficacy and internal power for better health outcomes. Patients are also aware of the significant role of their health care professionals on their health outcomes. Therefore, nurses are required to provide support for their patients' autonomy. The high level of internality HLOC among patients infers that patients want to assume more control and involvement in health care decision making that, if recognized by nurses and other health care professionals, will enhance the partnership model of care.

\section{Conflict of Interest}

The authors declare that there are no conflicts of interest.

\section{References}

[1] Hamdan Mansour, A., Marmash, L., Elayyan, R. and Hyarat, S. (2014) Difference in Perception between Nurses and Patients Related to Patients' Health Locus of Control. International Journal of Nursing practice, 20, 242-249. http://dx.doi.org/10.1111/ijn.12132

[2] Wallston, K.A., Stein, M.J. and Smith, C.A. (1994) Form C of the MHLC Scales: A Condition-Specific Measure of Locus of Control. Journal of Personality Assessment, 63, 534-533. http://dx.doi.org/10.1207/s15327752jpa6303 10

[3] Masters, K.S. and Wallston, K.A. (1994) Canonical Correlation Reveals Important Relations between Health Locus and Control, Coping, Affect, and Values. Journal of Health Psychology, 10, 719-731. http://dx.doi.org/10.1177/1359105305055332

[4] Auerbach, S.M., Clore, J.N., Kiesler, D.J., et al. (2002) Relation of Diabetic Patients' Health-Related Control Appraisals and Physician-Patient Interpersonal Impacts to Patients' Metabolic Control and Satisfaction with Treatment. Journal of Behavioral Medicine, 25, 17-31. http://dx.doi.org/10.1023/A:1013585617303

[5] Karter, A. and Ferrara, A. (2000) Self-Monitoring of Blood Sugar: Language and Financial Barriers in a Managed Care Population. Diabetes Care, 23, 477-482. http://dx.doi.org/10.2337/diacare.23.4.477

[6] Robison-Whelen, S. and Bodenheimer, C. (2004) Health Practices of Veterans with Unilateral Lower-Limb Loss: Identifying Correlates. Journal of Rehabilitation Research Development, 41, 453-460. http://dx.doi.org/10.1682/JRRD.2004.03.0453

[7] Trento, M., Tomelini, M., Basile, M., et al. (2008) The Locus of Control in Patients with Type 1 and Type 2 Diabetes Managed by Individual and Group Care. Diabetes Medicine, 25, 86-90. http://dx.doi.org/10.1111/j.1464-5491.2007.02319.x

[8] DeVito-Dabbs, A., Kim, Y., Hamdan-Mansour, A., Thibodeau, A. and McCurry, K. (2006) Health Locus of Control after Lung Transplantation: Implications for Managing Health. Journal of Clinical Psychology in Medical Settings, 13, 381-392.

[9] Darawad, M., Khalil, A., Hamdan-Mansour, A. and Nofeal, B. (2015) Perceived Exercise Self-Efficacy, Benefits and Barriers, and Commitment to a Plan for Exercise among Jordanians with Chronic Illnesses. Rehabilitation Nursing. http://dx.doi.org/10.1002/rnj.199

[10] Sareen. J., Cox, B.J., Clara, I. and Asmundson, G. (2005) The Relationship between Anxiety Disorders and Physical Disorders in the U.S. National Comorbidity Survey. Depress Anxiety, 21, 193-202. http://dx.doi.org/10.1002/da.20072

[11] Frasure-Smith, N. and Lespérance, F. (2006) Recent Evidence Linking Coronary Heart Disease and Depression. Canadian Journal of Psychology, 51, 730-751.

[12] Rozanski, A., Blumenthal, J.A., Davidson, K.W., Saab, P.G. and Kubzansky, L. (2005) The Epidemiology, Pathophysiology, and Management of Psychosocial Risk Factors in Cardiac Practice: The Emerging Field of Behavioral Cardiology. Journal of American College of Cardiology, 45, 637-651. http://dx.doi.org/10.1016/j.jacc.2004.12.005

[13] Chen, P.Y. and Chang, H.C. (2012) The Coping Process of Patients with Cancer. European Journal of Oncology Nursing, 16, 10-16. http://dx.doi.org/10.1016/j.ejon.2011.01.002

[14] MacDonald, B.H. (2001) Quality of Life in Cancer Care: Patients' Experiences and Nurses' Contribution. Journal of Oncology Nursing, 5, 32-41. http://dx.doi.org/10.1054/ejon.2000.0118

[15] Knappe, S. and Pinquart, M. (2009) Tracing Criteria of Successful Aging? Health Locus of Control and Well-Being in Older Patients with Internal Diseases. Psychology Health Medicine, 14, 201-212. http://dx.doi.org/10.1080/13548500802385717

[16] Hamdan-Mansour, A. (2010) Predictors of Hostility among University Students in Jordan. Scandanavian Journal of Caring Sciences, 24, 125-130. http://dx.doi.org/10.1111/j.1471-6712.2009.00695.x 
[17] Hamdan-Mansour, A., Aboshaiqah, A., Thultheen, I. and Salim, W. (2015) Psychological Wellbeing of Saudi Patients Diagnosed with Chronic Illnesses. Psychology, 6, 55-62. http://dx.doi.org/10.4236/psych.2015.61006

[18] Hamdan-Mansour, A., Al Abeiat, D., Alzoghaibi, I., Ghannam, B. and Hanouneh, S. (2015) Psychosocial and Sociodemographic Correlates of Life Satisfaction among Patients Diagnosed with Cancer in Jordan. Journal of Cancer Education, 30, 31-36. http://dx.doi.org/10.1007/s13187-014-0678-y

[19] Hamdan-Mansour, A., Ghannam, B., Al Abeiat, D., Al Badawi, T., Thulthian, I. and Shamali, I. (2014) Predicting Depression among Jordanian Patients Diagnosed with Physical Illnesses. Psychology, 5, 2120-2130. http://dx.doi.org/10.4236/psych.2014.519214

[20] Ghannam, B., Hamdan-Mansour, A., Arabiat, D., Azzeghaiby, S.N., Al Abeiat, D. and Badawi, T. (2014) Psychosocial Wellbeing of Patients Diagnosed with Coronary Artery Disease. Psychology, 5, 801-807. http://dx.doi.org/10.4236/psych.2014.58091

[21] Wallston, B.S., Wallston, K.A., Kaplan, G.D. and Maides, S.A. (1976) The Development and Validation of the Health Related Locus of Control (HLC) Scale. Journal of Consulting and Clinical Psychology, 4, 580-585. http://dx.doi.org/10.1037/0022-006X.44.4.580

[22] Westaway, M.S., Seage, J.R., Rheeder, P. and Van Zyl, D.G. (2005) The Effects of Social Support on Health, WellBeing and Management of Diabetes Mellitus: A Black South African Perspective. Ethnic Health, 10, 73-89. http://dx.doi.org/10.1080/1355785052000323047

[23] Fuertes, J.N., Boylan, S.L. and Fontanella, J.A. (2009) Behavioral Indices in Medical Care Outcome: The Working Alliance, Adherence, and Related Factors. Journal of General Internal Medicine, 24, 80-84. http://dx.doi.org/10.1007/s11606-008-0841-4

[24] Mohr, D.C., Boudewyn, A.C., Likosky, W., Levine, E. and Goodkin, D.E. (2001) Injectable Medication for the Treatment of Multiple Sclerosis: The Influence of Self-Efficacy Expectations and Injection Anxiety on Adherence and Ability to Self-Inject. Annals of Behavioral Medicine, 23, 125-134. http://dx.doi.org/10.1207/S15324796ABM2302_ 7

[25] Mackenbach, G.J., Borsboom, W.J., Nusselder, C.W., Looman, A. and Schrijvers, C.T. (2001) Determinants of Levels and Changes of Physical Functioning in Chronically III Persons: Results from the GLOBE Study. Journal of Epidemiology and Community Health, 55, 631-638. http://dx.doi.org/10.1136/jech.55.9.631

[26] Yehia, D., Callister, L. and Hamdan-Mansour, A. (2013) Prevalence and Predictors of Postpartum Depression among Arabic Muslim Jordanian Women Serving in the Military. Journal of Perinatal \& Neonatal Nursing, 27, 25-33. http://dx.doi.org/10.1097/JPN.0b013e31827ed6db

[27] Arabiat, D., ALqaissi, N. and Hamdan-Mansour, A. (2011) Children's Knowledge of Their Cancer Diagnosis and Treatment: Jordanian Mothers' Perceptions and Satisfaction with the Process. International Nursing Review, 58, $443-$ 449. http://dx.doi.org/10.1111/j.1466-7657.2011.00899.x

[28] Aljasem, L., Peyrot, M., Wissow, L. and Rubin, R. (2001) The Impact of Barriers and Self-Efficacy on Self-Care Behaviors in Type 2 Diabetes. Diabetes Education, 27, 393-404. http://dx.doi.org/10.1177/014572170102700309 